\title{
Calcilytic NPS2143 promotes proliferation and inhibits apoptosis of spontaneously hypertensive rat vascular smooth muscle cells via activation of the renin-angiotensin system
}

\author{
YONGLI ZHAO $^{1 *}$, NA TANG $^{1 *}$, DONGMEI XI $^{1}$, ZHEN HUANG $^{1}$, TIAN ZHANG ${ }^{1}$, \\ YONGMIN LIU ${ }^{1}$, LAMEI WANG ${ }^{2}$, YAN TANG ${ }^{3}$, HUA ZHONG ${ }^{1}$ and FANG HE ${ }^{1}$ \\ ${ }^{1}$ Department of Pathophysiology; ${ }^{2}$ The Centre of Medical Functional Experiments, Medical \\ College of Shihezi University; ${ }^{3}$ Department of Geriatrics, The First Affiliated Hospital of \\ Medical College of Shihezi University, Shihezi, Xinjiang 832002, P.R. China
}

Received March 4, 2019; Accepted January 17, 2020

DOI: $10.3892 /$ etm.2020.8759

\begin{abstract}
Vascular smooth muscle cell (VSMC) proliferation and apoptosis and the renin-angiotensin system (RAS) play critical roles in the development of essential hypertension. The activation of calcium-sensing receptor (CaSR), functionally expressed in VSMCs, inhibits cyclic adenosine monophosphate (cAMP) formation by elevating intracellular calcium $\left(\left[\mathrm{Ca}^{2+}\right]_{\mathrm{i}}\right)$ and then suppressing renin release. The present study aimed to investigate the effects of NPS2143-mediated inhibition of CaSR on VSMC proliferation and apoptosis in spontaneously hypertensive rat (SHR) VSMCs and to assess whether these effects were mediated by alterations to RAS signaling. Primary VSMCs were isolated from the aortas of SHRs and Wistar-Kyoto rats. SHR VSMCs were treated with CaSR antagonist NPS2143 and cell proliferation and CaSR and RAS-related protein expression levels were measured to assess the effect. The results indicated that NPS2143 treatment promoted SHR VSMC proliferation, lower CaSR expression levels and higher RAS-related proteins levels when compared with control treatment. Additional measurement of the expression levels of proteins related to proliferation, remodeling, apoptosis and RAS related proteins, as well as cell viability, cell cycle, cell apoptosis ratio, $\left[\mathrm{Ca}^{2+}\right]_{i}$, and the concentration of cAMP was performed after treatment with NPS2143, PLC inhibitor U73122, IP3 receptor antagonist 2-aminoethoxydiphenylborane (APB), adenylyl cyclase-V
\end{abstract}

Correspondence to: Professor Hua Zhong or Professor Fang He, Department of Pathophysiology, Medical College of Shihezi University, 59 North 2nd Road, Shihezi, Xinjiang 832002, P.R. China E-mail: 156696992@qq.com

E-mail: fangf2002shz@126.com

*Contributed equally

Key words: calcium-sensing receptor, renin-angiotensin system, proliferation, apoptosis inhibitor MDL12330A, angiotensin converting enzyme inhibitor captopril, angiotensin I receptor (AT1R) inhibitor losartan, NPS2143 + U73122, NPS2143 + 2-APB, NPS2143 + MDL12330A, NPS2143 + captopril and NPS2143 + losartan. The results suggested that NPS2143 promoted cell proliferation, inhibited cell apoptosis, decreased $\left[\mathrm{Ca}^{2+}\right]_{\mathrm{i}}$ and increased the expression of RAS compared with control treatments. NPS2143 + U73122 and NPS2143 + 2-APB enhanced the effects of NPS2143, while NPS2143 + MDL12330A, NPS2143 + captopril, NPS2143 + losartan attenuated the effected of NPS2143 in SHR VSMCs. Furthermore, the knockdown of AT1R by AT1R-short hairpin RNA also attenuated the effects of NPS2143 compared with NPS2143 alone. Collectively, these data indicated that NPS2143 promoted proliferation and inhibited apoptosis of VSMCs in SHRs, the effect of which was achieved by activation of RAS signaling.

\section{Introduction}

Approximately one billion people worldwide are affected by hypertension. Essential hypertension (EH) accounts for $90-95 \%$ of these cases, the progression of which is affected by both genetic and environmental factors (1-3). The underlying mechanisms of hypertension are complex. It is known that vascular smooth muscle cells (VSMCs) are located mainly in the arterial tunica media and act as critical determinants in vascular-related diseases (4). Excessive VSMC proliferation is involved in hypertension-induced maladaptive vascular remodeling $(5,6)$. An imbalance between proliferation and apoptosis may be important in the structural changes associated with vascular injury. In addition, the renin-angiotensin system (RAS) plays a pivotal role in regulating blood pressure and promoting the proliferation of VSMCs (7). Renin is the first rate-limiting enzyme of the RAS system and is closely linked to hypertension. Cyclic adenosine monophosphate (cAMP) plays a key role in this system (8). Another enzyme, tonin, directly catalyzes the formation of the plasma protein angiotensin II (Ang II) using renin tetradecapeptide as a substrate and angiotensin I (Ang I) (9). Ang II is a multifunctional peptide that exerts effects on VSMCs, including 
regulation of vasoconstriction, wall tension, cell growth and apoptosis, through its vasoconstrictive properties (10).

The relationship between $\mathrm{Ca}^{2+}$ and hypertension has been clinically well documented (11). A large number of studies have shown that a low calcium diet is a significant factor in hypertension and that calcium intake can effectively reduce blood pressure (BP), both effects which have been identified in animal models of hypertension $(12,13)$, though their underlying mechanisms are not well understood. Calcium sensitive receptor (CaSR), an extracellular $\mathrm{Ca}^{2+}$ receptor, is a member of the $\mathrm{C}$ subfamily of the G-protein-coupled receptor superfamily. Despite extensive current interest, the emergence of CaSR in the field of cardiovascular diseases was actually fairly recent. In 2003, the expression of CaSR in rat myocardium was first confirmed (14). Subsequently, scholars worldwide have confirmed the importance of CaSR's role in cardiovascular diseases, such as myocardial hypertrophy, ischemia-reperfusion injury, atherosclerosis and pulmonary hypertension $(15,16)$. Further research has determined that CaSR was functionally expressed in the outer membrane of the blood vessel wall, fibroblast cells and VSMCs (17). CaSR's main function is to maintain the homeostasis of $\mathrm{Ca}^{2+}$ and other metal ions throughout the body. Several studies have shown that CaSR may regulate BP, but the underlying mechanism is unknown. Rybczynska et al (18) reported that treatment with NPS2143, an allosteric inhibitor of CaSR, elevated BP in normotensive rats; however, in rats subjected to parathyroidectomy or treated with an Ang I receptor (AT1R) blocker (such as losartan) in the presence of a calcium-channel blocker or antagonist, elevated BP was not observed (19). Ogata et al (20) found that NPSR568 (R-568) decreased BP in uremic and spontaneously hypertensive rats (SHRs), but had no effect on normotensive rats. Atchison et al (12) and Ortiz-Capisano et al (21) suggested that CaSR was expressed in juxtaglomerular cells and its activation in turn activated the ryanodine receptor (RyR) via the phospholipase $\mathrm{C}$ (PLC)/inositol 1,4,5-triphosphate (IP3) pathway to augment intracellular calcium $\left(\left[\mathrm{Ca}^{2+}\right]_{i}\right)$ and inhibit cAMP formation, thereby suppressing renin release. These researchers hypothesized that the mechanism by which CaSR regulates blood pressure may be related to intervention by the RAS.

Previous studies have demonstrated that lower levels of the CaSR were associated with increased vascular remodeling, promoting the development of $\mathrm{EH}$ by activating the cAMP-RAS pathway; moreover, the CaSR agonist R568 was a viable suppressant of local RAS activity to relieve these symptoms in vivo $(22,23)$. However, the potential molecular mechanisms underlying this phenomenon remain to be elucidated. The present study was therefore conducted in order to determine whether NPS2143 promotes the proliferation of SHR VSMCs and whether this molecular mechanism is involved in activating the RAS signaling pathway.

\section{Materials and methods}

Drugs. NPS2143 was purchased from Tocris Bioscience Co., Ltd. U73122, captopril and losartan were obtained from Selleck Chemicals. 2-APB was purchased from Abcam and MDL12330A was obtained from ApexBio Technology LLC.
Cell culture and treatment. Primary VSMCs were isolated from thoracic aortas of 20 male Wistar-Kyoto (WKY) rats and 50 SHRs. Rats (age, 8 weeks; weight, 150-180 g) were purchased from Vital River Laboratory Animal Science and Technology Co., Ltd (license number: SCXK2012-0001) and were kept in an alternating 12-h light/dark cycle at a temperature of $20-25^{\circ} \mathrm{C}$, constant humidity with free access to food and water. This animal study was approved by the Institutional Animal Research Committee of Shihezi Medical University, and all animals received humane care in compliance with the Guide for the Care and Use of Laboratory Animals published by the National Institutes of Health (24). On the day of the experiment, rats were anaesthetized by the intraperitoneal injection of $30 \mathrm{mg} / \mathrm{l}$ pentobarbital sodium (Merck $\mathrm{KGaA}$ ) at a dose of $50 \mathrm{mg} / \mathrm{kg}$ and the chest was opened to extract the thoracic aorta. After surgery, the rats were euthanized by the intraperitoneal injection of pentobarbital sodium $(150 \mathrm{mg} / \mathrm{kg})$. Rat aorta was cleaned from adherent tissue, and the endothelium was denuded. Pieces of aorta $\left(1 \mathrm{~mm}^{2}\right)$ were cultured in Dulbecco's modified Eagle's medium/F12 (DMEM/F12; Gibco ${ }^{\circledR}$; Thermo Fisher Scientific, Inc.) supplemented with $20 \%$ FBS (Gibco ${ }^{\circledR}$; Thermo Fisher Scientific, Inc.) and $1 \%$ penicillin-streptomycin at $37^{\circ} \mathrm{C}$ in a $5 \% \mathrm{CO}_{2}$ humidified incubator in accordance with a previously published protocol (25). Cells migrated from the pieces of aorta after 7-9 days. Aortic pieces were then removed and VSMCs were left to proliferate. Experiments used VSMCs from passages 3-6 at 80-90\% confluence. Cell growth was arrested using serum-free DMEM-F12 to incubate the cells for $24 \mathrm{~h}$ before intervention. VSMCs were divided into 13 groups and treated as follows: i) Untreated WKY VSMC; ii) untreated SHR VSMC; iii) SHR VSMC treated with NPS2143 (1 $\mu \mathrm{M})$; iv) SHR VSMC treated with U73122 (10 $\mu \mathrm{M}$ (21); PLC-specific inhibitor); v) SHR VSMC treated with 2-aminoethoxydiphenylborane (2-APB; $100 \mu \mathrm{M}$; IP3 receptor antagonist) (21); vi) SHR VSMC treated with MDL12330A (10 $\mu \mathrm{M}$; adenylyl cyclase (AC)-V inhibitor) (26); vii) SHR VSMC treated with captopril $[100 \mu \mathrm{M}$; an angiotensin-converting enzyme (ACE) inhibitor] (27); viii) SHR VSMC treated with losartan $(10 \mu \mathrm{M}$, AT1R inhibitor) (28); ix) SHR VSMC treated with NPS2143 + U73122; x) SHR VSMC treated with NPS2143 + 2-APB group; xi) SHR VSMC treated with NPS2143 + MDL12330A; xii) SHR VSMC treated with NPS2143 + captopril; xiii) SHR VSMC treated with NPS2143 + losartan group. All the aforementioned treatment regimens were cultured at $37^{\circ} \mathrm{C}$ in a $5 \% \mathrm{CO}_{2}$ humidified incubator for $48 \mathrm{~h}$ prior to subsequent experimentation.

MTT assay-guided optimization. VSMCs $\left(5 \times 10^{3}\right.$ cells/well) were plated in 96-well plates and cultured for 12, 24, 48 and 72 $\mathrm{h}$ with NPS2143 of different concentrations $(0.01,0.03,0.1,0.3$ and $1 \mu \mathrm{M})(29)$, then treated with the designated drugs. MTT $(10 \mu \mathrm{l}, 5 \mathrm{mg} / \mathrm{ml})$ was added into each well and then incubated at $37^{\circ} \mathrm{C}$ for $4 \mathrm{~h}$. The supernatant was removed and $150 \mu \mathrm{l}$ of DMSO was added to each well. The absorbance at $490 \mathrm{~nm}$ was measured using a model 680 microplate reader (Bio-Rad Laboratories, Inc.). Cell proliferation ratio was calculated using the following formula: Ratio $=(\mathrm{A} 490$ value in test group- $\mathrm{A} 490$ value in control group)/A490 value in control group x100\%.

Flow cytometry analysis of cell cycle distribution. Cell cycle distribution was determined using propidium iodide 
(PI) staining according to the manufacturer's instructions [MultiSciences (Lianke) Biotech Co., Ltd.]. Following optimal time treatments with the designated drug interventions, cells were harvested and fixed with $70 \%$ ethanol overnight at $4^{\circ} \mathrm{C}$. Fixed cells were collected by centrifugation $\left(1,000 \times \mathrm{g}\right.$ for $5 \mathrm{~min}$ at $\left.4^{\circ} \mathrm{C}\right)$, washed twice using PBS, and incubated with $1 \mathrm{ml}$ of PI staining buffer $(20 \mu \mathrm{g} / \mathrm{ml}$ PI and $50 \mu \mathrm{g} / \mathrm{ml} \mathrm{RNaseA}$ ) at room temperature for $30 \mathrm{~min}$ in the dark. Thereafter, cellular fluorescence was measured by flow cytometry (BD FACSAria ${ }^{\mathrm{TM}}$ III Cell Sorter; cat. no. 648282; BD Biosciences). Flow cytometry data analysis was conducted performed using the FlowJo 7.6.1 software (FlowJo LLC).

Apoptosis assays. Apoptosis was detected using an annexin V-FITC/PI apoptosis detection kit or annexin V-APC/PI apoptosis detection kit according to the manufacturer's instructions [MultiSciences (Lianke) Biotech Co., Ltd.]. Briefly, VSMCs were plated into six-well plates and incubated with drugs for optimal intervals using the results from MTT assay. The cells were harvested, washed twice with pre-chilled PBS, and centrifuged $\left(1,000 \mathrm{x} \mathrm{g}\right.$ for $5 \mathrm{~min}$ at $\left.4^{\circ} \mathrm{C}\right)$, followed by staining with annexin V-FITC/PI or annexin V-APC/PI at $4^{\circ} \mathrm{C}$ for $10 \mathrm{~min}$ in the dark and then stained cells were analyzed by flow cytometry (BD FACSAria ${ }^{\mathrm{TM}}$ III Cell Sorter; cat. no. 648282; BD Biosciences). Flow cytometry data analysis of the proportion of apoptotic cells was performed using the FlowJo 7.6.1 software (Flowjo LLC).

Fluo-3/acetoxymethyl (Fluo-3/AM) measurements of $\left[\mathrm{Ca}^{2+}\right]_{i}$. VSMCs were cultured where the cell density was adjusted to $1 \times 10^{5}$ cells $/ \mathrm{ml}$ with the indicated drugs for optimal time intervals, then loaded with $5 \mu \mathrm{M}$ fluo-3/AM (Beijing Solarbio Science \& Technology Co., Ltd.) for $40 \mathrm{~min}$ at $37^{\circ} \mathrm{C}$ in the dark. The VSMCs were then washed twice with $\mathrm{Ca}^{2+}(0.14 \mathrm{~g} / \mathrm{l})$ HEPES-buffered saline (HBS) to remove the extracellular fluo-3/AM and incubated further in $\mathrm{Ca}^{2+} \mathrm{HBS}$ for $20 \mathrm{~min}$ at $37^{\circ} \mathrm{C}$. Next, confocal microscopy (model: Zeiss LSM 510 META; Zeiss AG) was performed to analyze the fluorescence intensity induced by fluo-3.

Immunofluorescence analysis. VSMCs were fixed in 4\% paraformaldehyde for $20 \mathrm{~min}$ at room temperature and blocked with 5\% BSA (Sigma-Aldrich; Merck KGaA) for $30 \mathrm{~min}$ at $37^{\circ} \mathrm{C}$. The cells were then co-incubated with either CaSR (1:200; cat. no. ab19347; Abcam) and Renin (1:100; cat. no. bs-6184R; BIOSS) primary antibodies or CaSR (1:200; cat. no. ab223360) and AT1R (1:50; cat. no. ab9391; Abcam) primary antibodies overnight at $4^{\circ} \mathrm{C}$. On the following day, the cells were brought to room temperature over $1 \mathrm{~h}$ and washed 3 times (5 min each time) with PBS. Goat tetramethylrhodamine (TRITC)-conjugated anti-mouse (1:50; cat. no. BA1089; Boster Biological Technology), goat FITC-conjugated anti-rabbit secondary antibody (1:50; cat. no. BA1105; Boster Biological Technology), goat TRITC-conjugated anti-rabbit (1:50; cat. no. BA1090; Boster Biological Technology) or goat FITC-conjugated anti-mouse secondary antibody (1:50; cat. no. BA1101; Boster Biological Technology) diluted using 5\% BSA were added in the dark and the cells were incubated at room temperature for $1 \mathrm{~h}$. After being washed with PBS, the cells were treated with $0.5 \mu \mathrm{M}$ DAPI for $10 \mathrm{~min}$ at $37^{\circ} \mathrm{C}$.
Next, the cells were examined and images were captured using confocal microscopy.

ELISA. ELISA kits (Elabscience Biotechnology Co., Ltd.) were used to determine the levels of Renin (cat. no. E-EL-R0030c) and Ang II (cat. no. E-EL-R1430c) in the cell culture medium and cAMP (cat. no. E-EL-0056c) from the cell lysate, each specific measurement method was performed according to the manufacturer's protocols. Optical absorbance values were read at $450 \mathrm{~nm}$ (Bio-Rad Model 3550-UV; Bio-Rad Laboratories, Inc.).

Western blot analysis. After specific drug treatments, cells were incubated in lysis buffer (PMSF:RIPA, 1:100; Sigma-Aldrich; Merck $\mathrm{KGaA}$ ) for $20 \mathrm{~min}$ on ice. After insoluble debris was pelleted by centrifugation at $12,000 \mathrm{x} \mathrm{g}$ for $15 \mathrm{~min}$ at $4^{\circ} \mathrm{C}$, the supernatants were collected and protein concentrations were assessed by the bicinchoninic acid method. After boiling the samples for $10 \mathrm{~min}$, the protein samples $(10 \mu \mathrm{g} / \mathrm{lane})$ were fractionated by SDS-PAGE (10-12\% polyacrylamide gels), transferred to polyvinylidene fluoride membranes (EMD Millipore) and blocked with 5\% non-fat milk for $2 \mathrm{~h}$ at room temperature. The membranes were then incubated overnight at $4^{\circ} \mathrm{C}$ using appropriate dilutions of primary antibodies against CaSR (1:1,000; cat. no.; Abcam), proliferating cell nuclear antigen (PCNA, 1:250; cat. no. BM0104; Boster Biological Technology), smooth muscle actin $\alpha$ ( $\alpha$-SMA; 1:500; cat. no. BM0002; Boster Biological Technology, Wuhan, China), calponin (1:400; cat. no. BM4088; Boster Biological Technology), osteopontin (OPN; 1:1,000; cat. no. ab8448; Abcam), renin (1:250; cat. no. bs-6184R; BIOSS), AT1R (1:1,000; cat. no. ab9391; Abcam, UK), Bcl-2 (1:200; cat. no. BA0412; Boster Biological Technology), Bax (1:200; cat. no. BA0315; Boster Biological Technology) and $\beta$-actin (1:1,000; cat. no. TA-09; ZSGB-Bio; OriGene Technologies, Inc.). Membranes were then washed three times with Tris-buffered saline containing $0.1 \%$ Tween 20 and incubated with horseradish peroxidase-conjugated secondary antibodies (1:20,000; Boster Biological Technology) for $2 \mathrm{~h}$ at room temperature. Detection was performed with an enhanced chemiluminescence system (Pierce; Thermo Fisher Scientific, Inc.). Band intensity was quantified using Bio-Rad Quantity One software (version 4.3.0; Bio-Rad Laboratories, Inc.) with $\beta$-actin as an internal control.

Adenovirus-mediated downregulation of AT1R in VSMCs. VSMCs $\left(1 \times 10^{5} / \mathrm{ml}\right)$ were prepared and infected at a multiplicity of infection of 100 with shRNA scrambled or AT1R down-regulating AT1R-shRNA adenovirus 67, 68, 69 (Shanghai GeneChem Co., Ltd.) for $48 \mathrm{~h}$ at $37^{\circ} \mathrm{C}$ in a $5 \% \mathrm{CO}_{2}$ humidified incubator, following which interference efficiency was assessed by either reverse transcription-quantitative PCR (RT-qPCR) or western blot analysis. The target sequences were as follows: shRNA scrambled, 5'-TTCTCCGAACGT GTCACGT-3'; shAT1R-67, 5'-GGCCAGCGTCTTTCTTCT CAA-3'; shAT1R-68, 5'-CAGCGTGAGCTTCAACCTCTA-3' and shAT1R-69, 5'-GGGCTGGGCCTTACCAAGAAT-3'.

$R T$ - $q P C R$. Total RNA was extracted from cultured VSMCs using TRIzol ${ }^{\circledR}$ Reagent (Invitrogen; Thermo Fisher Scientific, 
Inc.) according to manufacturer's protocol. First-strand cDNA synthesis was performed using a TIANScript RT kit according to manufacturer's protocol (Tiangen Biotech Co., Ltd.). The temperature step protocol for the reverse transcription reaction $70^{\circ} \mathrm{C}$ for $5 \mathrm{~min}$, on ice for $2 \mathrm{~min}, 42^{\circ} \mathrm{C}$ for $50 \mathrm{~min}$ and lastly $95^{\circ} \mathrm{C}$ for $5 \mathrm{~min}$. The consequent cDNA products were used as the PCR templates. Subsequent qPCR was performed using SYBR $^{\mathrm{TM}}$ Green PCR Master Mix (Thermo Fisher Scientific, Inc.) according to manufacturer's protocol with the Applied Biosystems 7500 Real-Time PCR system (Thermo Fisher Scientific, Inc.). The primer sequences used for qPCR were as follows: AT1R forward, 5'-GCTTCAACCTCTACGCCA GTGTG-3' and reverse, 5'-CAGCCAGATGATGATGCAGGT GAC-3' and GADPH forward, 5'-TGGCCTTCCGTGTTCCTA C-3' and reverse, 5'-GAGTTGCTGTTGAAGTCGCA-3'. The thermocycling conditions were as follows: Initial denaturation at $95^{\circ} \mathrm{C}$ for $2 \mathrm{~min}$, followed by 45 cycles of $95^{\circ} \mathrm{C}$ for $15 \mathrm{sec}$, $60^{\circ} \mathrm{C}$ for $15 \mathrm{sec}$, and $72^{\circ} \mathrm{C}$ for $1 \mathrm{~min}$. The Relative expression was normalized to that of GAPDH and was quantified using the $2^{-\Delta \Delta \mathrm{Cq}}$ method (30).

Statistical analysis. Data are presented as the mean \pm SEM. Experimental groups were compared using one-way ANOVA, followed by Bonferroni correction. An unpaired Student's t-test was used for direct comparisons. $\mathrm{P}<0.05$ was considered a statistically significant difference. Statistical analysis was performed using SPSS 22.0 software (IBM Corp.).

\section{Results}

NPS2143 promotes SHR VSMCs proliferation and expression of renin and ATIR. To investigate the effect of NPS2143 on the proliferation of SHR VSMCs and the expression of CaSR, renin and AT1R in these cells, optimal concentration and time of exposure to NPS2143 was first measured using MTT. The results indicated that NPS2143 promoted cell proliferation in SHR VSMCs compared with control and that $1 \mu \mathrm{M}$ for $48 \mathrm{~h}$ was the optimal treatment concentration and time $(\mathrm{P}<0.05$; Fig. 1A and B). However, NPS2143 had no effect on WKY VSMCs (P>0.05; Fig. S1). Therefore, $1 \mu \mathrm{M}$ for $48 \mathrm{~h}$ was used as the treatment condition in the subsequent experiments in SHR VSMCs. Western blotting $(\mathrm{P}<0.05$; Fig. 1D-F) and immunofluorescence staining showed that the expression of CaSR was markedly lower in SHR VSMCs compared with WKY VSMCs (Fig. $1 \mathrm{G}$ and $\mathrm{H}$ ), and that this reduction was further enhanced by NPS2143 treatment $(\mathrm{P}<0.05)$. The expression of renin and AT1R was higher in SHR VSMCs than in WKY VSMCs and these levels were further increased by NPS2143 treatment compared with no treatment $(\mathrm{P}<0.05$; Fig. $1 \mathrm{C}$ and $\mathrm{E}-\mathrm{H})$. In addition, $\mathrm{CaSR}$ and renin appeared co-localized in the cell membrane and cytoplasm (Fig. 1G). CaSR and AT1R were also co-localized in the cell membrane and cytoplasm (Fig. 1H).

NPS2143 promotes SHR VSMC proliferation by regulating the PLC-IP3/AC-V/cAMP/RAS signaling pathway. To further explore the proliferative effect of NPS2143 on SHR VSMCs, cells were treated with NPS2143 (an antagonist of CaSR), U73122 (a specific inhibitor of PLC), 2-APB (a specific antagonist of the IP3 receptor), MDL12330A (an AC-V inhibitor), captopril (an ACE inhibitor), losartan (an AT1R inhibitor) and
NPS2143 combined with PLC-IP3/AC-V/cAMP/RAS signaling pathway inhibitors. Western blot analysis indicated that the protein levels of two contractile/differentiated VSMC phenotype marker proteins ( $\alpha$-SMA and calponin) were decreased in SHR VSMCs compared with WKY VSMCs, while the expression levels of OPN, a synthetic/dedifferentiated phenotype marker protein, and PCNA were significantly increased in SHR VSMCs compared with WKY VSMCs $(\mathrm{P}<0.05$; Fig. 2A-E). Compared with the untreated SHR VSMC group, the protein levels of $\alpha$-SMA and calponin were decreased and OPN and PCNA levels were significantly increased in the NPS2143, U73122 and 2-APB treated groups. However, the MDL12330A, captopril, and losartan treated groups exhibited the opposite effect $(\mathrm{P}<0.05$; Fig. 2A-E). Compared with the NPS2143 group, the expression levels of $\alpha$-SMA and calponin were decreased and the expression of OPN and PCNA were increased in the NPS2143 + U73122 and NPS2143 + 2-APB groups, however, the expression levels of $\alpha$-SMA and calponin were increased, and the expression of OPN and PCNA were decreased in the NPS2143 + MDL12330A, NPS2143 + captopril, NPS2143 + losartan groups compared with the NPS2143 group $(\mathrm{P}<0.05$; Fig. 2A-E).

An MTT assay was used to further examine cell proliferation and flow cytometry was used to examine the regulation of cell cycle progression from the $\mathrm{G}_{0} / \mathrm{G}_{1}$ to $\mathrm{S}+\mathrm{G}_{2} / \mathrm{M}$ phases. Data suggested that the proportion of cells in the $G_{0} / G_{1}$ phase was lower and the proportion of cells in the $S+\mathrm{G}_{2} / \mathrm{M}$ phase was higher in the SHR group compared with the WKY group. The proportion of $G_{0} / G_{1}$ phase cells was lowered further by treatment with NPS2143, U73122 and 2-APB, while it was increased by MDL12330A, captopril and losartan, compared with the SHR group. Compared with the SHR group, the proportion of cells in the $S+\mathrm{G}_{2} / \mathrm{M}$ phase was significantly increased by treatment with NPS2143, U73122 and 2-APB, whilst it was significantly decreased by MDL12330A, captopril and losartan treatment $(\mathrm{P}<0.05$; Fig. 2F-H). NPS2143 + U73122 and NPS2143 + 2-APB further promoted cell cycle progression, but NPS2143 + MDL12330A, NPS2143 + captopril, and NPS2143 + losartan had the opposite effect compared with the NPS2143 group ( $\mathrm{P}<0.05$; Fig. 2F-H).

NPS2143 inhibits cell apoptosis in SHR VSMCs via the $P L C-I P 3 / A C-V / c A M P / R A S$ signaling pathway. To investigate whether NPS2143 had an effect on SHR VSMC apoptosis via the PLC-IP3/AC-V/cAMP/RAS signaling pathway, the apoptotic rate and the ratio of $\mathrm{Bax} / \mathrm{Bcl}-2$ were examined. The results showed that the number of Annexin-V/PI positive cells and the Bax/Bcl-2 ratio was reduced in SHR VSMCs compared with WKY VSMCs. Apoptosis levels were further reduced by treatment with NPS2143, U73122 and 2-APB, while they were increased by MDL12330A, captopril and losartan, compared with the SHR group. NPS2143 + U73122 and NPS2143 +2 -APB reduced the apoptotic rate and $\mathrm{Bax} / \mathrm{Bcl}-2$ ratio compared with cells treated with NPS2143 only, but NPS2143 + MDL12330A, NPS2143 + captopril, and NPS2143 + losartan had the opposite effect $(\mathrm{P}<0.05$; Fig. 3$)$.

NPS2143 activates the RAS system in SHR VSMCs by reducing $\left[\mathrm{Ca}^{2+}\right]_{i}$. To test the role and mechanisms of CaSR in regulating the RAS system, the levels of $\left[\mathrm{Ca}^{2+}\right]_{\mathrm{i}}$ were measured 

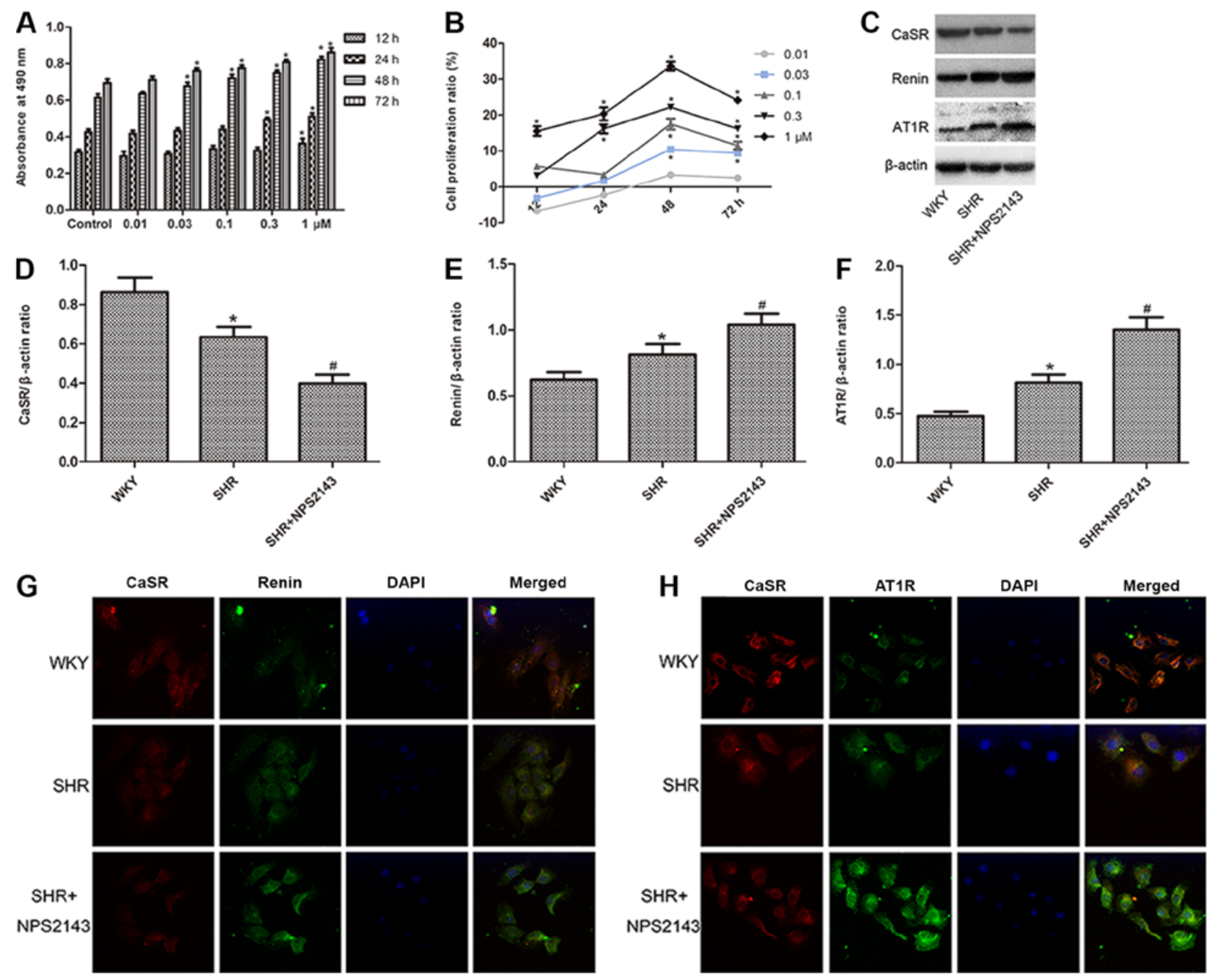

Merged

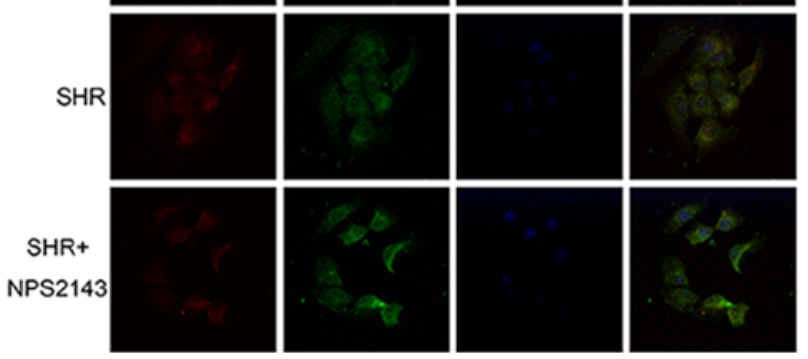

Figure 1. Determination of cell proliferation levels and the expression of CaSR, renin and AT1R in SHRs VSMCs. (A) Effects of NPS2143 at different concentrations of NPS2143 $(0.01,0.03,0.1,0.3$ and $1 \mu \mathrm{M})$ for 12, 24, 48 and $72 \mathrm{~h}$ on the absorbance at $490 \mathrm{~nm}$ of SHR VSMCs was tested by MTT assay. (B) Effects of NPS2143 at different concentrations $(0.01,0.03,0.1,0.3$ and $1 \mu \mathrm{M})$ for 12, 24, 48 and $72 \mathrm{~h}$ on the cell proliferation ratio of SHR VSMCs as tested by MTT assay. "P<0.05 vs. the control group at the respective time point. (C) CaSR, renin and AT1R protein expression levels were assessed by western blot analysis. (D) CaSR, (E) renin and (F) AT1R levels were quantified in relation to $\beta$-actin levels. (G) Immunofluorescence indicated that CaSR co-localized with renin. (H) Immunofluorescence analysis indicated that CaSR co-localized with AT1R. Magnification, $\mathrm{x} 400$. The data are presented as the mean \pm SEM, $\mathrm{n}=3$. ${ }^{\text {"P }}<0.05$ vs. WKY group; ${ }^{\text {"P }}<0.05$ vs. the SHR group. AT1R, angiotensin II type 1 receptor; CaSR, calcium-sensing receptor; SHR, VSMCs from spontaneously hypertensive rats; VSMC, vascular smooth muscle cell; WKY, VSMCs from Wistar Kyoto rats.

and a lower level of $\left[\mathrm{Ca}^{2+}\right]_{\mathrm{i}}$ in SHR VSMCs was observed compared with WKY VSMCs. $\left[\mathrm{Ca}^{2+}\right]_{\mathrm{i}}$ was lowered further by treatment with NPS2143, U73122 and 2-APB. The levels of $\left[\mathrm{Ca}^{2+}\right]_{\mathrm{i}}$ decreased in the NPS2143 + U73122 and NPS2143 + 2-APB groups compared to the NPS2143 group ( $<<0.05$; Fig. 4A and B). In addition, western blotting results showed that AT1R protein expression was higher in SHR VSMCs compared with WKY VSMCs and this was further increased by NPS2143, U73122 and 2-APB treatment and lowered by MDL12330A, captopril and losartan treatment $(\mathrm{P}<0.05)$. AT1R protein expression levels increased in the NPS2143 + U73122, NPS2143 + 2-APB groups, but decreased in the NPS2143 + MDL12330A, NPS2143 + captopril, and NPS2143 + losartan groups compared to the NPS2143 group $(\mathrm{P}<0.05$; Fig. $4 \mathrm{C}$ and D). ELISA results showed that cAMP and renin concentrations exhibited the same trend as AT1R $(\mathrm{P}<0.05$; Fig. 4E and F), though neither the captopril nor losartan groups exhibited significant differences compared with the
SHR group, whilst the NPS2143 + captopril and NPS2143 + losartan groups had no effects compared with NPS2143 groups ( $\mathrm{P}>0.05$; Fig. $4 \mathrm{E}$ and $\mathrm{F})$. Ang II concentration also exhibited the same trend as AT1R $(\mathrm{P}<0.05$; Fig. $4 \mathrm{G})$, though the losartan and NPS2143 + losartan groups had no effect on Ang II concentration compared with SHR and NPS2143 groups, respectively ( $\mathrm{P}>0.05$; Fig. 4G).

Regulatory effects of AT1R downregulation on NPS2143induced SHR VSMCs proliferation and apoptosis. To further determine whether AT1R affected NPS2143-induced functional events in SHR VSMCs, as well as the molecular mechanism, VSMCs were transfected with AT1R-shRNA. RT-qPCR $(\mathrm{P}<0.05$; Fig. S2A and $\mathrm{B})$ and western blotting $(\mathrm{P}<0.05$; Fig. S2C-E) confirmed the highest interference efficiency of shAT1R-67, which was used in later experiments. The results indicated that shAT1R-67 increased the expression of $\alpha$-SMA, calponin $(\mathrm{P}<0.05$; Fig. 5A-C) and the proportion of cells in 
A

D

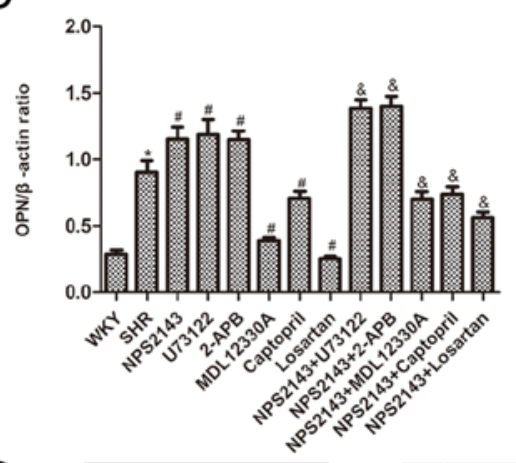

G
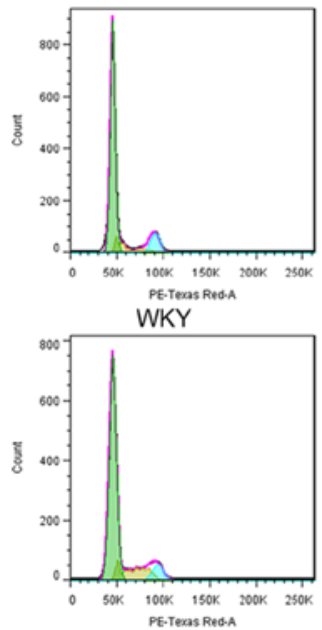

MDL12330A

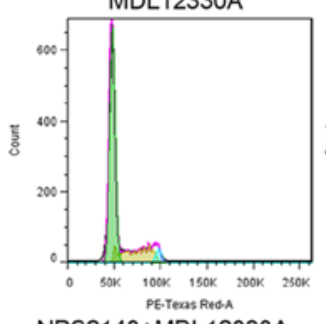

NPS2143+MDL12330A

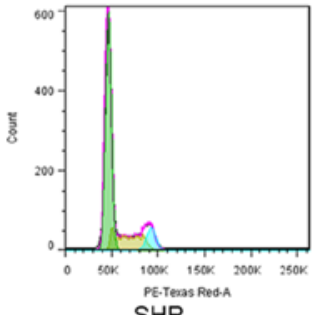

SHR

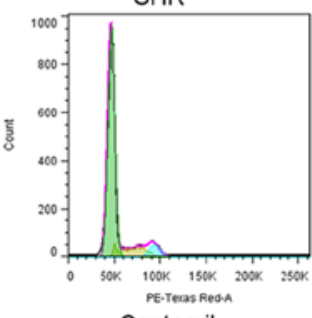

Captopril

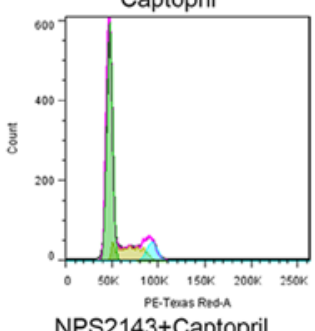

NPS2143+Captopril

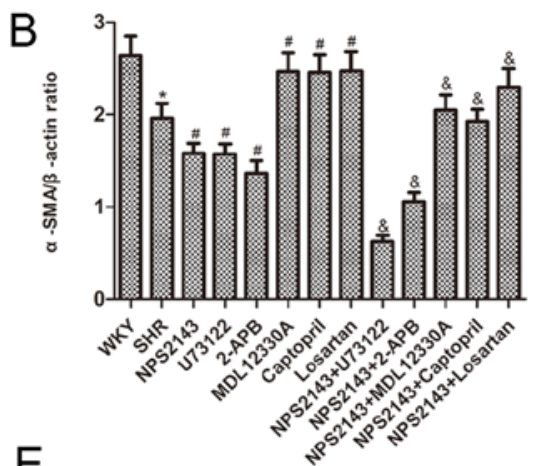

E

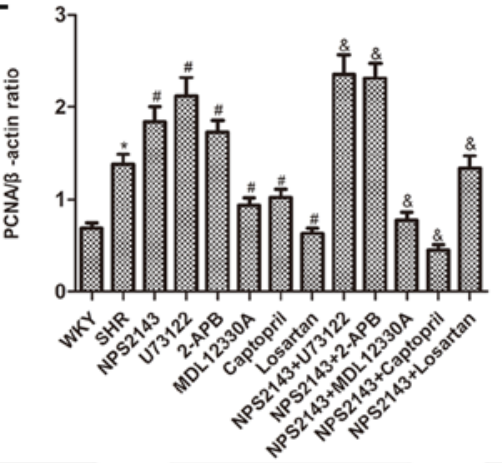

$\mathrm{F}$
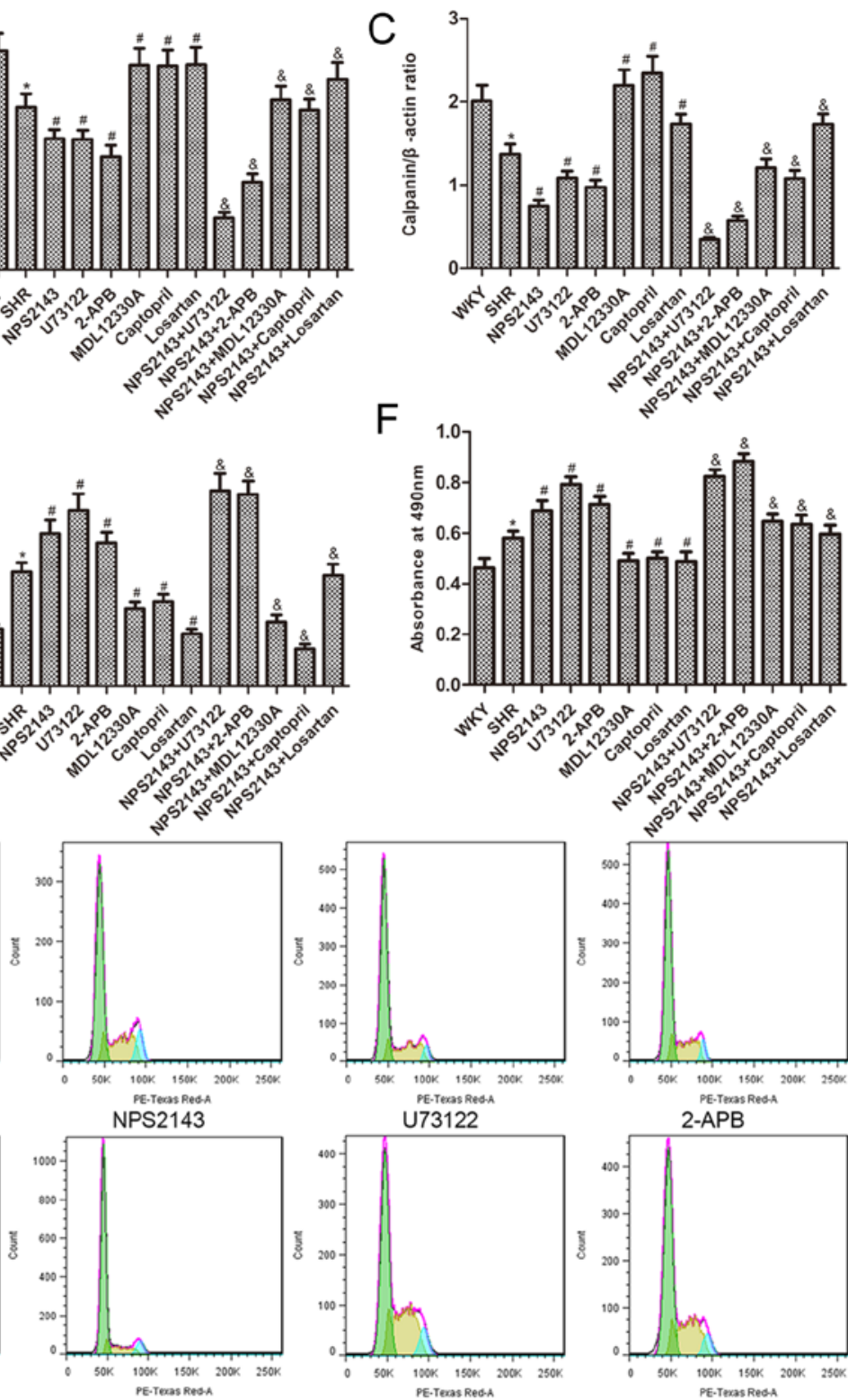

Losartan

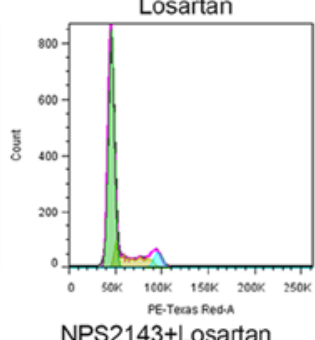

2-APB

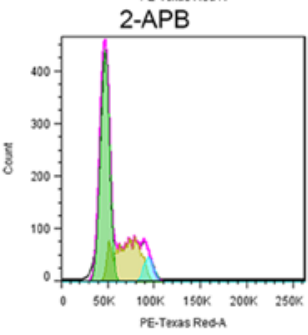

NPS $2143+2-A P B$ NPS $2143+\mathrm{U} 73122$

$\mathrm{H}$

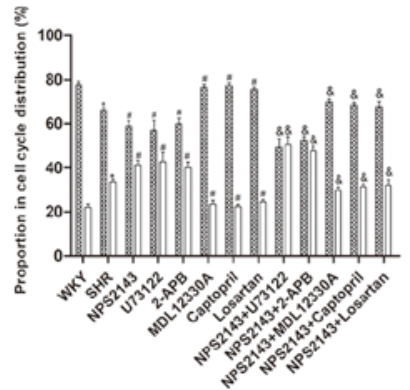

Figure 2. Western blot analysis of proliferation and remodeling-associated protein expression and MTT and cell cycle regulation analysis of proliferation in SHR VSMCs. (A) Western blot analysis of $\alpha$-SMA, calponin, OPN and PCNA protein expression. (B) Densitometric analysis of $\alpha$-SMA expression. (C) Densitometric analysis of calponin expression. (D) Densitometric analysis of OPN expression. (E) Densitometric analysis of PCNA expression. (F) MTT assay was used to test VSMC proliferation. (G) Flow cytometry was used to examine cell cycle distribution in the different treatment groups $\left(\right.$ green, $\mathrm{G}_{0} / \mathrm{G}_{1}$ phase, yellow, $\mathrm{S}$ phase, blue, $\mathrm{G}_{2} / \mathrm{M}$ phase) and $(\mathrm{H})$ Quantitative analysis of flow cytometry data. VSMCs in the intervention groups were all derived from spontaneously hypertensive rats. Data are presented as the mean \pm SEM, $n=6$. ${ }^{*} \mathrm{P}<0.05$ vs. WKY; ${ }^{\#} \mathrm{P}<0.05$ vs. SHR; ${ }^{\text {P }}<0.05$ vs. NPS2143. $\alpha-\mathrm{SMA}$, smooth muscle $\alpha$-actin; OPN, osteopontin; PCNA, proliferating cell nuclear antigen; SHR, VSMCs from spontaneously hypertensive rats; VSMC, vascular smooth muscle cell; WKY, VSMCs from Wistar Kyoto rats.

the $G_{0} / G_{1}$ phase $(P<0.05$; Fig. $5 G$ and $H)$, while it decreased the expression levels of OPN, PCNA (Fig. 5A, D and E) and cell proliferation $(\mathrm{P}<0.05$; Fig. $5 \mathrm{~F})$, as well as the proportion of cells in the $\mathrm{S}+\mathrm{G}_{2} / \mathrm{M}$ phase $(\mathrm{P}<0.05$; Fig. $5 \mathrm{G}$ and $\mathrm{H})$ compared with control group. The results also indicated that shAT1R-67 increased the apoptosis $(\mathrm{P}<0.05$; Fig. $6 \mathrm{~A}$ and $\mathrm{B})$ and $\mathrm{Bax} / \mathrm{Bcl}-2$ 

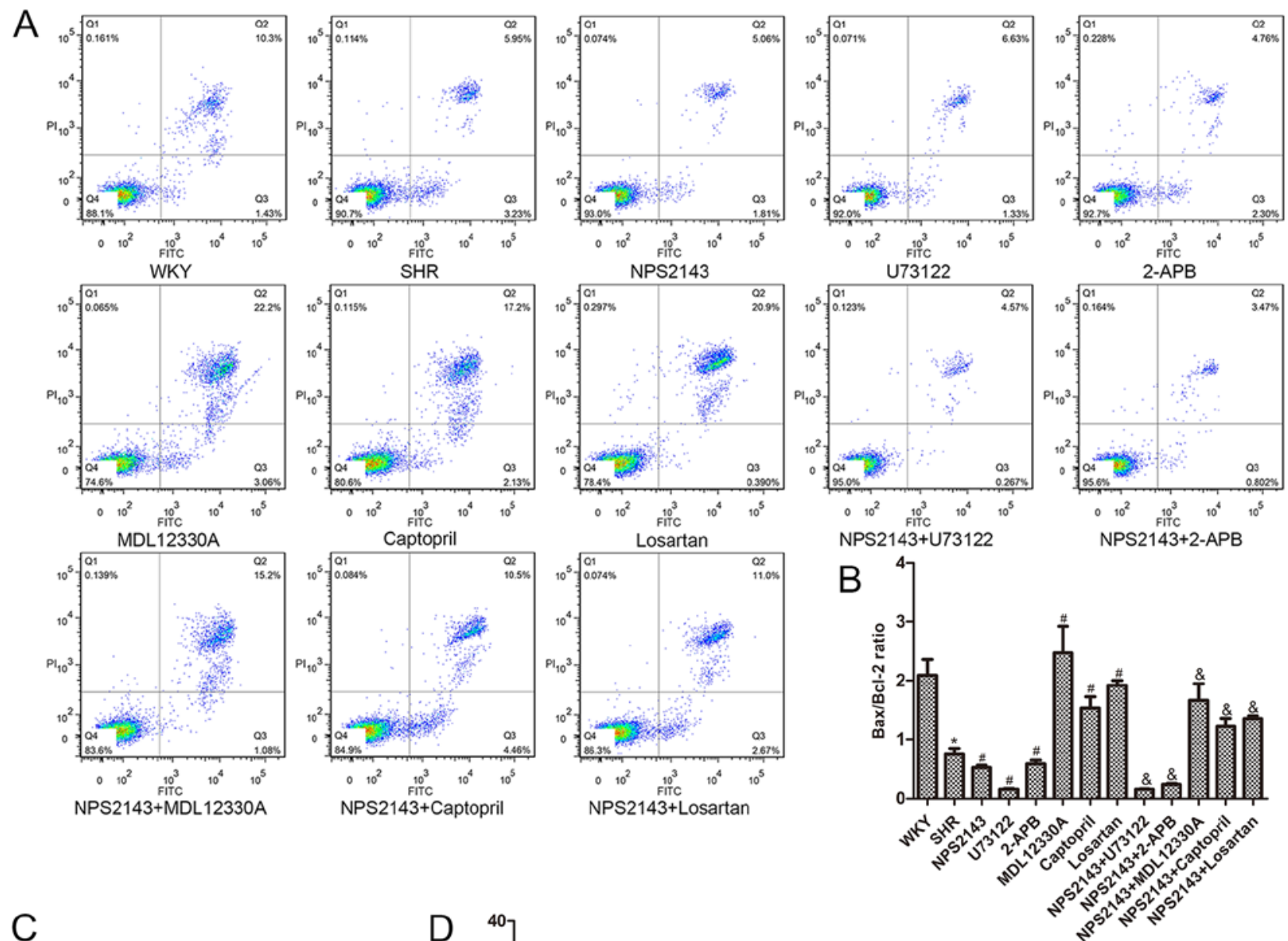

NPS2143+2-APB
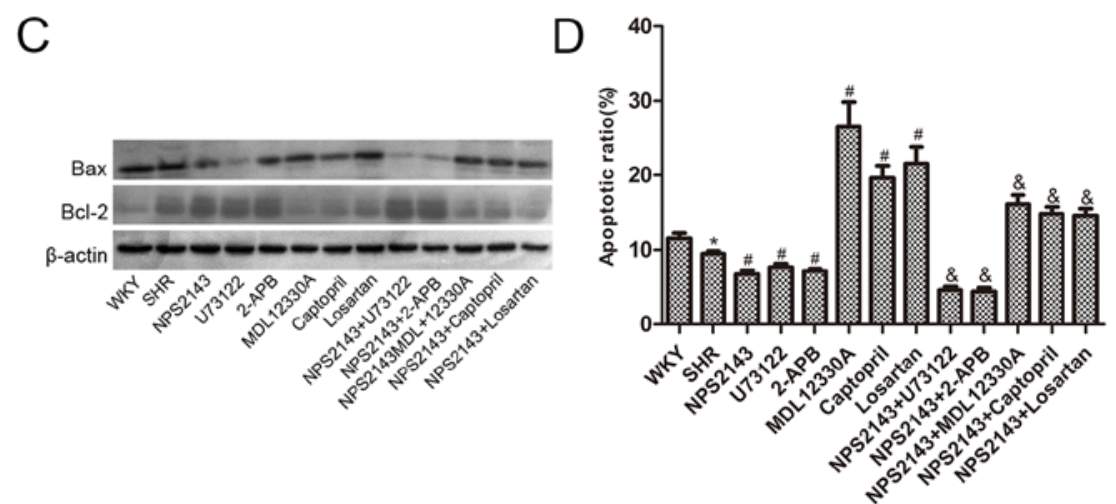

Figure 3. Determination of the apoptotic rate and levels of apoptosis-related proteins in SHR VSMCs. (A) Annexin-V/PI staining and flow cytometry was used to determine the level of apoptosis. (B) Cells in Q2 and Q3 were classed as apoptotic and the results were analyzed quantitatively. (C) Bax and Bcl-2 protein expression was assessed by western blot analysis and (D) the ratio of Bax/Bcl-2 quantified. VSMCs in the intervention groups were all derived from spontaneously hypertensive rats. The data are expressed as the mean $\pm \mathrm{SEM}, \mathrm{n}=3$. ${ }^{\mathrm{P}} \mathrm{P}<0.05$ vs. WKY; ${ }^{\text {}} \mathrm{P}<0.05$ vs. the SHR group; ${ }^{\circ} \mathrm{P}<0.05$ vs. the NPS2143 group. SHR, VSMCs from spontaneously hypertensive rats; VSMC, vascular smooth muscle cell; WKY, VSMCs from Wistar Kyoto rats.

ratios $(\mathrm{P}<0.05$; Fig. 6C and $\mathrm{D})$ compared with control group. Furthermore, the effect of NPS2143-mediated inhibition of apoptosis $(\mathrm{P}<0.05$; Fig. 6) was weakened by pretreatment with shAT1R-67. Taken together, the results of the present study suggested that activation of the RAS system was involved in NPS2143-induced VSMC proliferation and apoptosis.

\section{Discussion}

In the present study, the impact of CaSR inhibition on SHR VSMC proliferation and apoptosis was investigated via disruption to the PLC-IP 3 /AC-V/cAMP/RAS signaling pathway. Additionally, the relationship between CaSR and changes in AC (cAMP content) and RAS activity in VSMCs was explored. The results suggested that CaSR inhibition contributed to VSMC proliferation and attenuated apoptosis and that CaSR inhibition activated the RAS through the PLC-IP3/AC-V/cAMP pathway. Furthermore, downregulation of AT1R attenuated the effect of NPS2143 on the promotion of proliferation and the inhibition of apoptosis in SHR VSMCs.

Although research into CaSR is extensive, the study of CaSR in the cardiovascular field started relatively late. A previous study has demonstrated that CaSR may have a role in regulating $\mathrm{BP}$, the mechanism remains to be elucidated (31). 


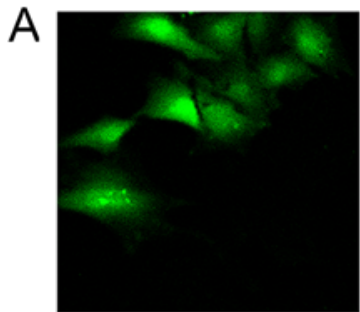

WKY

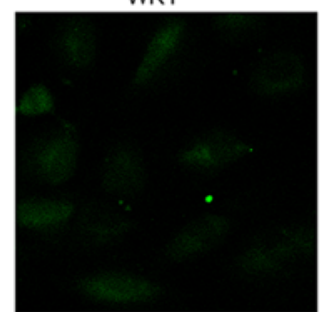

NPS2143+U73122

B.

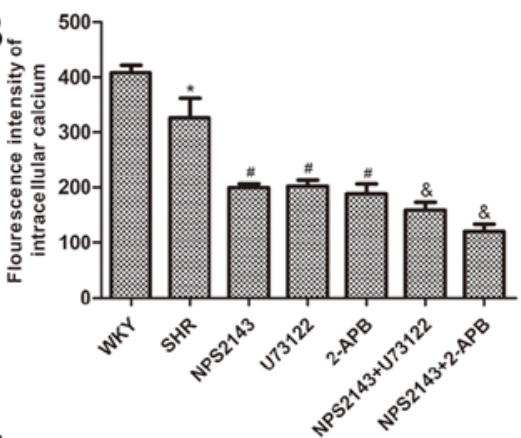

E

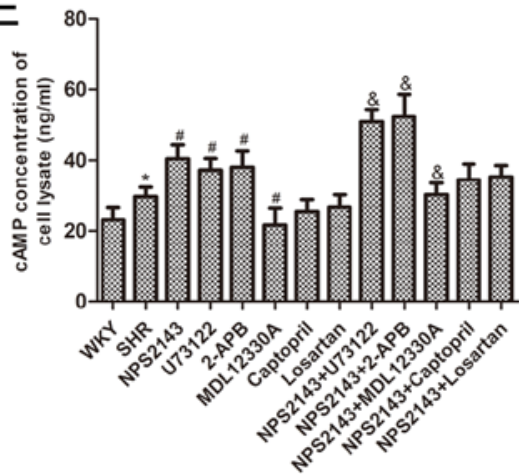

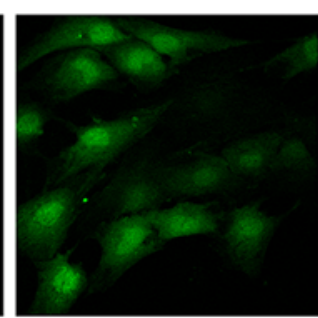

SHR

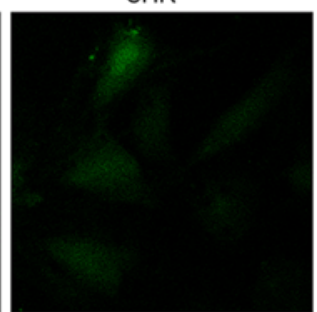

NPS2143+2-APB

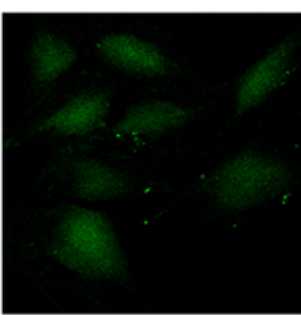

NPS2143

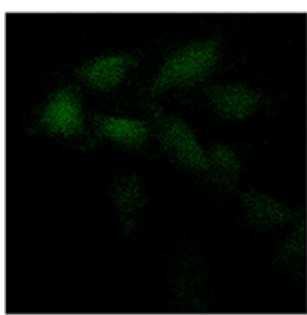

U73122

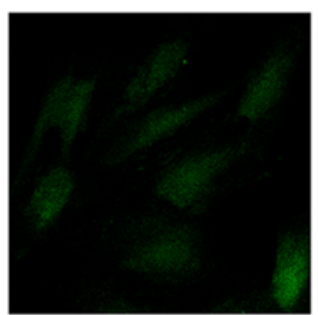

2-APB

C
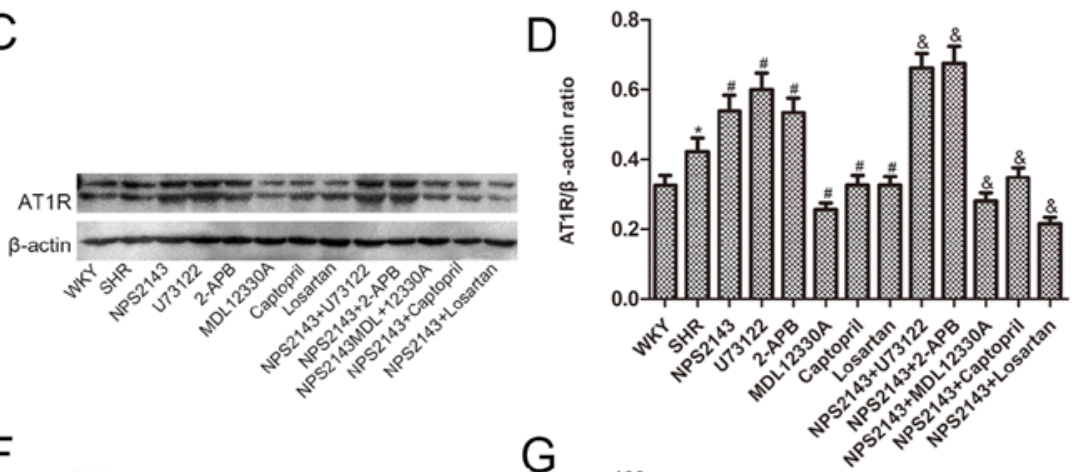

F

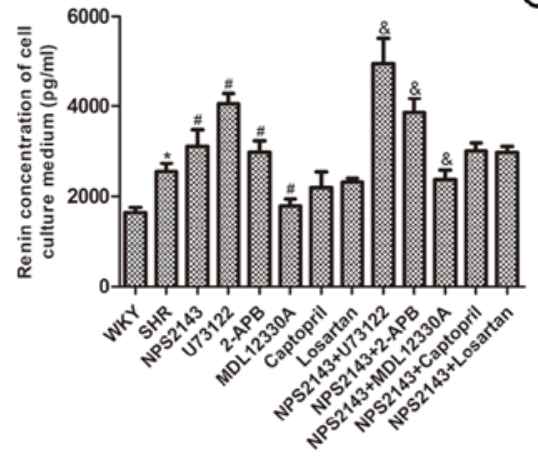

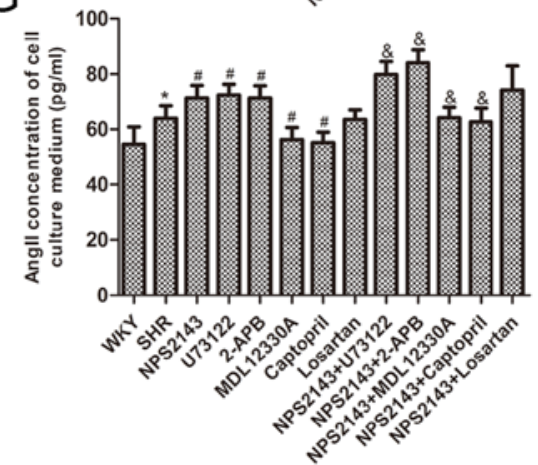

Figure 4. Determination of $\left[\mathrm{Ca}^{2+}\right]_{\mathrm{i}}$ AT1R protein expression and cAMP, renin and Ang II levels in SHR VSMCs. (A) Changes in the intensity of fluorescence of $\left[\mathrm{Ca}^{2+}\right]_{i}$ were recorded with a laser scanning confocal microscope under different treatment conditions. Magnification, $\mathrm{x} 400$. (B) Quantitative analysis of fluorescence intensity. (C) AT1R protein expression assayed by western blot analysis. (D) Densitometric analysis of AT1R expression. (E) ELISA detection of cAMP concentration. (F) ELISA detection of renin concentration. (G) ELISA detection of Ang II concentration. VSMCs in the intervention group were all derived from spontaneously hypertensive rats. The data are expressed as the mean \pm SEM. $n=3$ for $(A-D), n=6$ for $(E-G)$. ${ }^{*} \mathrm{P}<0.05$ vs. WKY group; ${ }^{\#} \mathrm{P}<0.05$ vs. SHR group; ${ }^{\circledR} \mathrm{P}<0.05$ vs. NPS 2143 group. WKY, VSMCs from Wistar Kyoto rats; SHR, VSMCs from spontaneously hypertensive rats; Ang II, Angiotensin II; AT1R, Ang II type 1 receptor; cAMP, cyclic adenosine monophosphate; VSMC, vascular smooth muscle cell; [Ca $\left.{ }^{2+}\right]_{\mathrm{i},}$ intracellular calcium.

Smajilovic et al (32) confirmed that CaSR was functionally expressed in rat aortic VSMCs and that it affected their proliferation. Previous studies from our research group have also demonstrated similar results (22). Maillard et al (33) suggested that calcimimetic R-568 could regulate the release of renin through $\mathrm{CaSR}$ and that renin plays a crucial role in the occurrence of EH. The authors of the current study previously reported that the CaSR agonist, R-568, could lower BP and reduce VSMC proliferation and remodeling by suppressing local RAS activity (23), but whether NPS2143, an allosteric inhibitor of CaSR, could play an opposing role in
SHR VSMCs was not clear. Previous research results could not adequately explain whether the anti-hypertensive effect mediated by the CaSR agonist R-568 was related to inhibition of the PLC-IP3/AC-V/cAMP/RAS signaling pathway, and therefore the present study was designed to explore this question in depth. In the present study, CaSR was antagonized with NPS2143 in vitro and the results suggested that NPS2143 promoted SHR VSMC proliferation and decreased the expression of CaSR compared with control treatment. However, RAS signaling proteins (renin and AT1R) were increased in SHRs VSMCs compared with WKY VSMCs and further increased 
A

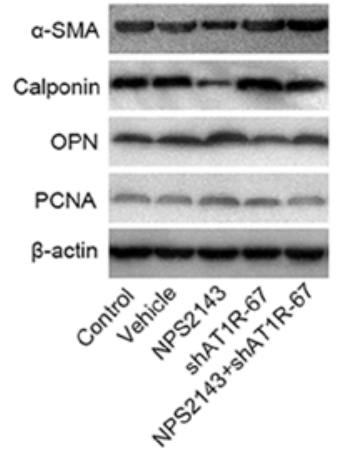

D

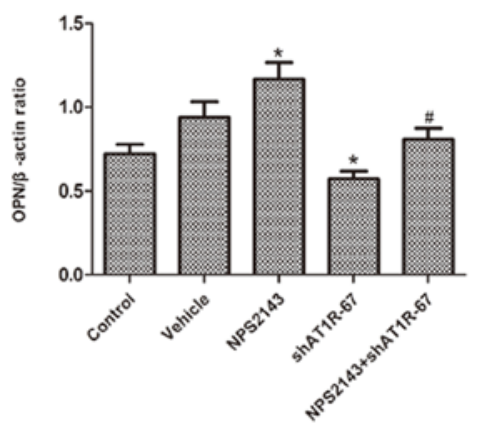

B

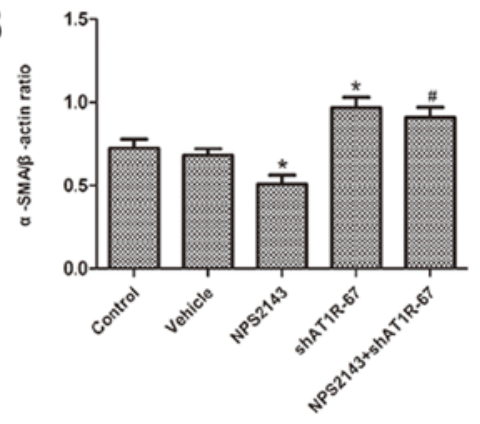

E

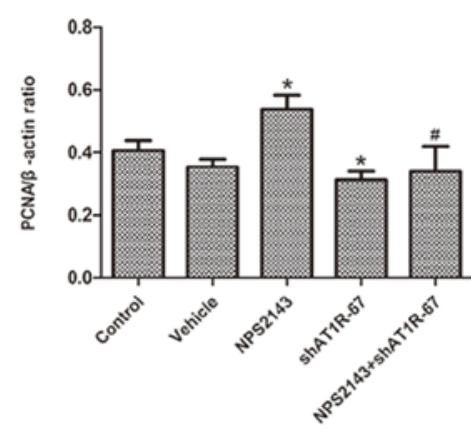

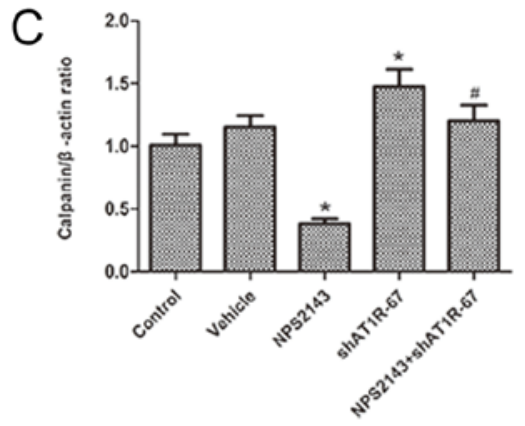

$\mathrm{F}$

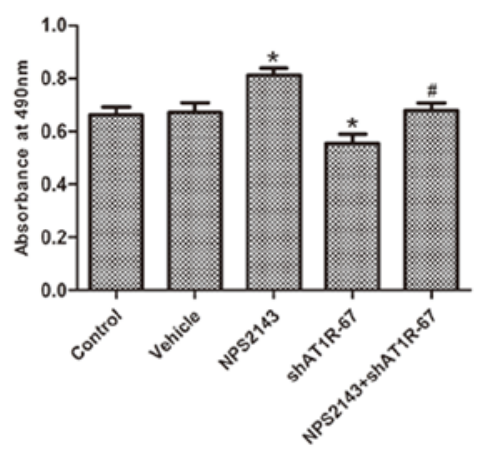

G
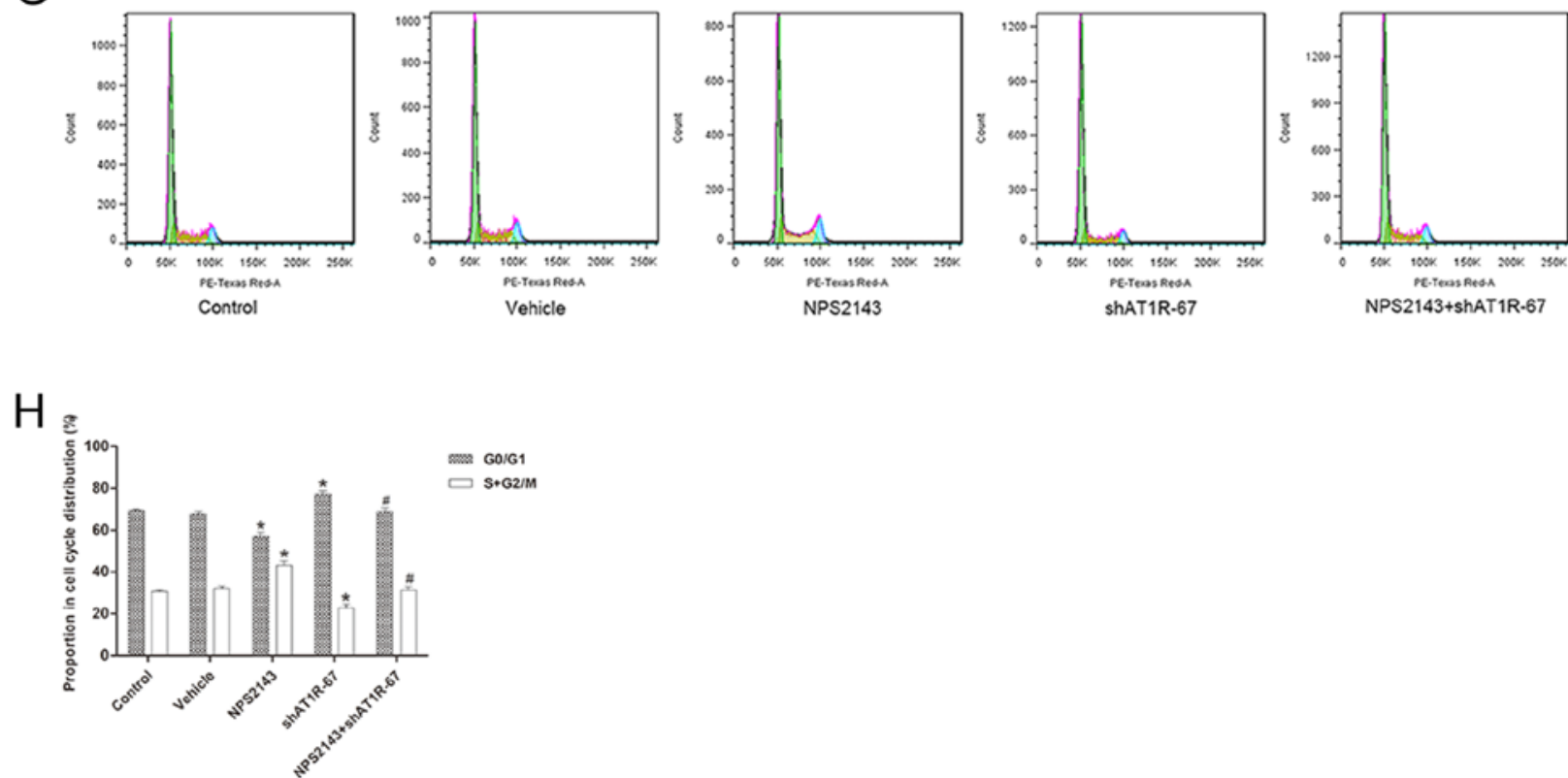

Figure 5. NPS2143 promotes proliferation by downregulating AT1R expression in SHR VSMCs. (A) Western blot analysis of $\alpha$-SMA, calponin, OPN and PCNA protein expression. (B) Densitometric analysis of $\alpha$-SMA expression. (C) Densitometric analysis of calponin expression. (D) Densitometric analysis of OPN expression. (E) Densitometric analysis of PCNA expression. (F) MTT assay was used to test VSMC viability. (G) Flow cytometry was used to examine cell cycle distribution (green, $G_{0} / G_{1}$ phase, yellow, $S$ phase, blue, $G_{2} / M$ phase). (H) Quantitative analysis of flow cytometry data. Data are expressed as the mean \pm SEM, $n=3,{ }^{*} \mathrm{P}<0.05$ vs. control group; ${ }^{*} \mathrm{P}<0.05$ vs. NPS2143 group. $\alpha$-SMA, smooth muscle $\alpha$-actin; OPN, osteopontin; PCNA, proliferating cell nuclear antigen; AT1R, Ang II type 1 receptor; SHR, VSMCs from spontaneously hypertensive rats; VSMC, vascular smooth muscle cell.

by NPS2143 treatment. Based on these data it may be hypothesized that NPS2143 promoted SHR VSMCs proliferation, potentially through activation of the RAS.

VSMC proliferation is associated with vascular sclerosis. Over-proliferation of VSMCs can lead to smaller vessel lumen and thicker vessel walls, which can play an important role in the pathogenesis of hypertension (6). In the present study, VSMCs were treated with NPS2143, U73122, 2-APB, MDL12330A, captopril, losartan and NPS2143 combined with these
PLC-IP3/AC-V/cAMP/RAS signaling pathway inhibitors to explore whether NPS2143 promoted SHR VSMC proliferation through the PLC-IP3/AC-V/cAMP/RAS pathway. Expression of proliferation-related phenotypic proteins, including $\alpha$-SMA and calponin (two contractile/differentiated VSMC phenotype marker proteins) (34), OPN (a synthetic/dedifferentiated VSMC phenotype marker protein) (35) and PCNA (an important index of cell proliferation) (36), as well as cell viability and cell cycle stages were examined. The results suggested 
A
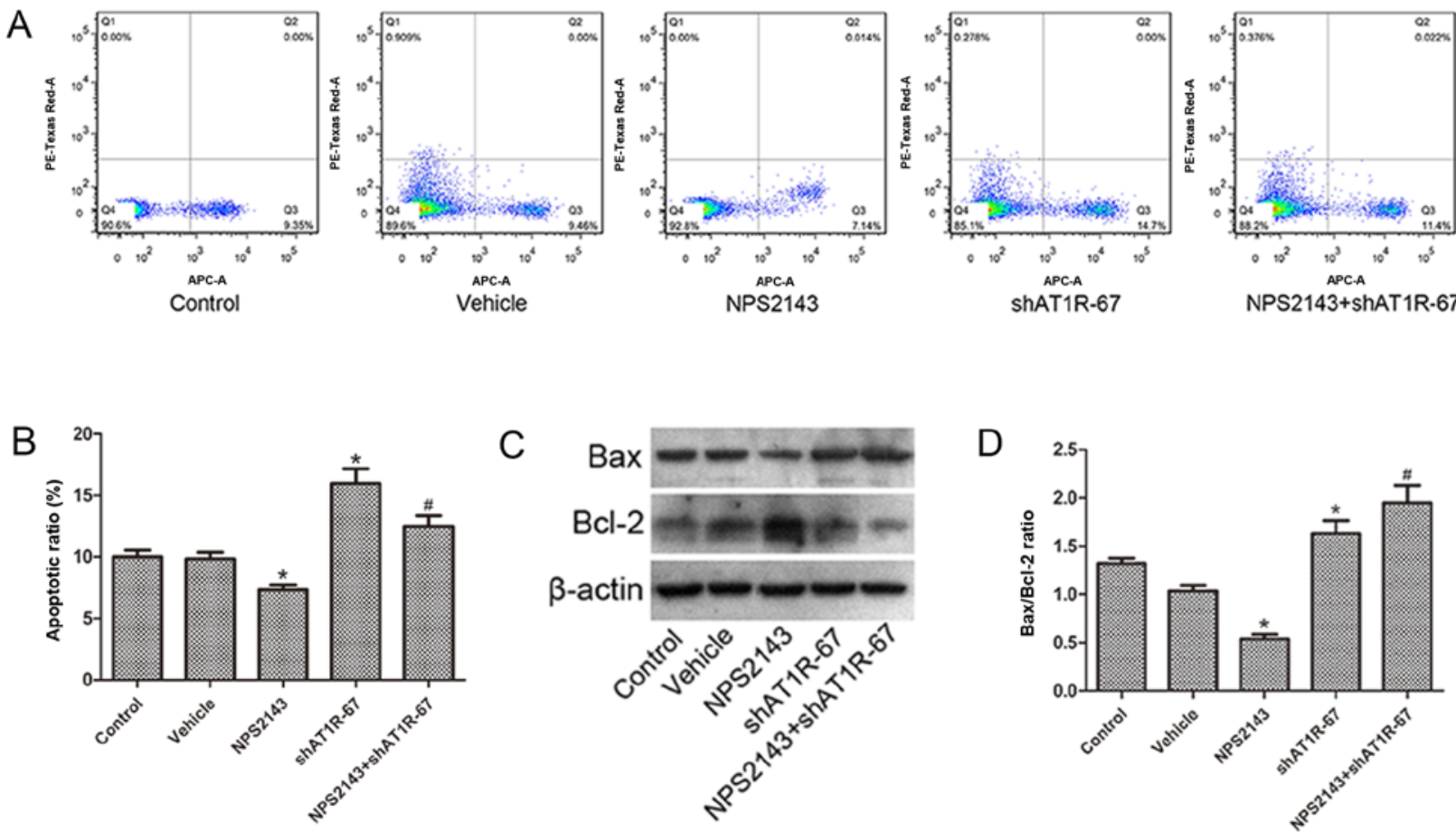

Figure 6. NPS2143 inhibits apoptosis by downregulating AT1R expression in SHR VSMCs. (A) The level of apoptosis was examined using flow cytometry and the upper right area and the lower right area were regarded as apoptotic areas. (B) Quantitative analysis of flow cytometry results. (C) Bax and Bcl-2 protein expression assayed by western blot analysis. (D) The ratio of the $\mathrm{Bax} / \mathrm{Bcl}-2$. The data are expressed as the mean $\pm \mathrm{SEM}, \mathrm{n}=3$. ${ }^{*} \mathrm{P}<0.05 \mathrm{vs}$. control group; ${ }^{\#} \mathrm{P}<0.05$ vs. NPS2143 group. SHR, VSMCs from spontaneously hypertensive rats; VSMC, vascular smooth muscle cell; vehicle, shRNA scrambled transfection; shRNA, short hairpin RNA.

that the expression of $\alpha$-SMA and calponin was lower, while OPN and PCNA levels were higher in SHR VSMCs compared with WKY VSMCs. Additionally, cell viability was increased and cell cycle progression was accelerated in SHR VSMCs compared with WKY VSMCs, which were in turn potentiated by NPS2143. NPS2143 in combination with PLC-IP3 pathway blockers had a greater effect on SHR VSMCs than NPS2143 alone, while NPS2143 combined with AC-V/cAMP/RAS pathway blockers had the opposite effect. Although cell proliferation is emphasized as playing a key role in vascular remodeling, the growth of VSMCs is considered to be the result of a balance between proliferation and apoptosis. VSMCs apoptosis in the small arteries of young SHRs has been reported, suggesting that the reduction of the apoptotic rate in resistance vessels contributes to VSMC growth in this model (37). Activation of the stromal cell-derived factor- $1 \alpha /$ $\mathrm{C}-\mathrm{X}-\mathrm{C}$ motif chemokine receptor 4 axis and NPS2143 could counteract CaSR activation-mediated ischemia/reperfusion injury and promote surgical flap survival through inhibition of caspase-3/caspase-9-related cell apoptosis and enhancement of neovascularization (38). The results of the present study suggest that apoptosis was reduced in SHR VSMCs compared with WKY VSMCs and that NPS2143 and NPS2143 combined with PLC-IP $3 /$ AC-V/cAMP/RAS pathway blockers exhibited a trend opposite to that of proliferation.

In order to investigate the mechanism by which NPS2143 affects proliferation and apoptosis of SHR VSMCs, the current study focused on the roles of cAMP, the RAS and $\left[\mathrm{Ca}^{2+}\right]_{i}$ signaling molecules that connect PLC/IP3 and the AC-V/cAMP/RAS pathway. Ortiz-Capisano et al (21) shown that the activation of CaSR in turn activates the RyR through the PLC/IP3 pathway, increases $\left[\mathrm{Ca}^{2+}\right]_{\mathrm{i}}$ and inhibits the formation of cAMP, thereby suppressing renin release in primary cultures of isolated mouse juxtaglomerular cells. $\left[\mathrm{Ca}^{2+}\right]_{\mathrm{i}}$ was investigated using fluo-3/AM and found to be expressed at lower levels in SHR VSMCs than WKY VSMCs and to be decreased with NPS2143, U73122 and 2-APB treatment. NPS2143 combined with U73122 and 2-APB reduced $\left[\mathrm{Ca}^{2+}\right]_{\mathrm{i}}$ levels compared with NPS2143. Cytosolic calcium may play a regulatory role in apoptosis and chelating intracellular or extracellular calcium; moreover, application of a calcium channel blocker or of calmodulin antagonists has been shown to delay or even eliminate apoptosis $(39,40)$. Therefore, it is possible that NPS2143 may promote proliferation and inhibit the apoptosis of SHR VSMCs not only through the decrease of $\left[\mathrm{Ca}^{2+}\right]_{\mathrm{i}}$ due to blockage of the PLC/IP3 pathway, but also through a subsequent change in $\left[\mathrm{Ca}^{2+}\right]_{i}$, which mediates the activity of the RAS. The RAS plays both a vital physiological role in regulating vascular function and a pathological role in vascular injury, through its role in endothelial dysfunction and vascular remodeling and inflammation $(10,41)$. Renin converts angiotensinogen to Ang I, which is then cleaved by ACE to form Ang II (42). Ang II, binds to AT1R and promotes a VSMC phenotypic switch, from a contractile to a proliferative and synthetic phenotype, leading to changes in the contractile machinery, vascular hypertrophy/proliferation and secretion of contractile marker proteins (43). Numerous studies have suggested that ACE inhibitors and AT1R blockers may contribute to the regression of vascular wall growth through activation of proapoptotic pathways $(44,45)$. Rybczynska et al $(18)$ reported that blocking calcium channels and the blockade of AT1 receptors prevented the hypertensive effect of calcilytic NPS2143 
in normotensive rats. In the current study, the expression of cAMP, renin, Ang II and AT1R was increased in SHR VSMCs compared with WKY VSMCs, and was further increased by NPS2143 treatment. NPS2143 combined with PLC-IP3 pathway blockers enhanced the effect of NPS2143 on SHR VSMCs, while NPS2143 combined with AC-V/cAMP/RAS pathway blockers inhibited the effect of NPS2143 on SHR VSMCs. These results suggested that the CaSR antagonist NPS2143 promoted SHR VSMC proliferation and inhibited apoptosis by activating the AC-V/cAMP/RAS pathway.

Finally, in order to further elucidate the molecular mechanism by which the RAS contributes to the proliferation and apoptosis induced by NPS2143, a loss-of-function mutation in AT1R was established through adenovirus infection. Prior transfection with AT1R shRNA by adenovirus infection resulted in $\alpha$-SMA and calponin upregulation and PCNA and OPN downregulation, as well as inhibition of the proliferation and promotion of apoptosis induced by NPS2143. These results are consistent with the suggestion that regulation of RAS pathways is the molecular mechanism by which CaSR contributes to proliferation and apoptosis in SHR VSMCs.

The present study has limitations. The RAS includes the classical and non-classical RAS, while the current only focused on classical RAS. Whether non-classical RAS also has a role in CaSR-mediated cell proliferation and apoptosis remains to be elucidated.

In conclusion, the results of the present study suggested that a reduction in the expression of CaSR can lead to the proliferation and apoptosis of SHR VSMCs by activation of the RAS. CaSR antagonist NPS2143 promoted cell proliferation and inhibited apoptosis, while the use of a CaSR agonist combined with a RAS blocker interfered with abnormal proliferation and apoptosis of VSMCs. This method of treatment may have a positive role in lowering blood pressure and reversing vascular remodeling in the treatment of hypertension.

\section{Acknowledgements}

Not applicable.

\section{Funding}

The present study was supported by the National Natural Science Foundation of China (grant no. 31560287) and the Xinjiang Graduate Student Research Innovation Project (grant no. XJ2019G105).

\section{Availability of data and materials}

The datasets used and/or analyzed during the current study are available from the corresponding author on reasonable request.

\section{Authors' contributions}

$\mathrm{YZ}, \mathrm{FH}$ and $\mathrm{HZ}$ conceived and designed the experiments. $\mathrm{YZ}$, NT, DX and ZH performed the experiments. YZ, TZ, YL, LW and YT analyzed the data. YZ, HZ and FH wrote or modified the paper. All authors contributed to and approved the final draft of the manuscript.

\section{Ethics approval and consent to participate}

The study was approved by the Ethics Committee of Shihezi Medical University (approval no. A2017-175-01; Shihezi, China).

\section{Patient consent for publication}

Not applicable.

\section{Competing interests}

The authors declare that they have no competing interests.

\section{References}

1. Kearney PM, Whelton M, Reynolds K, Muntner P, Whelton PK and He J: Global burden of hypertension: Analysis of worldwide data. Lancet 365: 217-223, 2005.

2. Writing Group Members; Mozaffarian D, Benjamin EJ, Go AS, Arnett DK, Blaha MJ, Cushman M, Das SR, de Ferranti S, Després JP, et al: Heart Disease and Stroke Statistics-2016 Update: A Report From the American Heart Association. Circulation 133: e338-e360, 2016.

3. Svetkey LP, Harris EL, Eden M, Vollmer WM, Meltesen GT, Ricchiuti V, Williams G, Appel LJ, Bray GA, Moore TJ, et al: Modulation of the BP response to diet by genes in the renin-angiotensin system and the adrenergic nervous system. Am J Hypertens 24: 209-217, 2011.

4. Cai X: Regulation of smooth muscle cells in development and vascular disease: Current therapeutic strategies. Expert Rev Cardiovasc Ther 4: 789-800, 2006.

5. Haudenschild CC, Grunwald J and Chobanian AV: Effects of hypertension on migration and proliferation of smooth muscle in culture. Hypertension 7: I101-1104, 1985.

6. Belo VA, Guimarães DA and Castro MM: Matrix metalloproteinase 2 as a potential mediator of vascular smooth muscle cell migration and chronic vascular remodeling in hypertension. J Vasc Res 52: 221-231, 2016.

7. Bavishi C, Bangalore S and Messerli FH: Renin angiotensin aldosterone system inhibitors in hypertension: Is there evidence for benefit independent of blood pressure reduction? Prog Cardiovasc Dis 59: 253-261, 2016.

8. Churchill PC: Second messengers in renin secretion. Am J Physiol 249: 175-184, 1985.

9. Genest J, Nowaczynski W, Boucher R, Kuchel O and Rojo-Ortega JM: Aldosterone and renin in essential hypertension. Can Med Assoc J 113: 421-431, 1975.

10. Touyz RM: The role of angiotensin II in regulating vascular structural and functional changes in hypertension. Curr Hypertens Rep 5: 155-164, 2003.

11. Allender PS, Cutler JA, Follmann D, Cappuccio FP, Pryer J and Elliott P: Dietary calcium and blood pressure: A meta-analysis of randomized clinical trials. Ann Intern Med 124: 825-831, 1996.

12. Atchison DK, Ortiz-Capisano MC and Beierwaltes WH: Acute activation of the calcium-sensing receptor inhibits plasma renin activity in vivo. Am J Physiol Regul Integr Comp Physiol 299: R1020-R1026, 2010.

13. Ayachi S: Increased dietary calcium lowers blood pressure in the spontaneously hypertensive rat. Metabolism 28: 1234-1238, 1979.

14. Wang R, Xu C, Zhao W, Zhang J, Cao K, Yang B and Wu L: Calcium and polyamine regulated calcium-sensing receptors in cardiac tissues. Eur J Biochem 270: 2680-2688, 2003.

15. Yamamura A, Yamamura H, Guo Q, Zimnicka AM, Wan J, Ko EA, Smith KA, Pohl NM, Song S, Zeifman A, et al: Dihydropyridine $\mathrm{Ca}(2+)$ channel blockers increase cytosolic $[\mathrm{Ca}(2+)]$ by activating $\mathrm{Ca}(2+)$-sensing receptors in pulmonary arterial smooth muscle cells. Circ Res 112: 640-650, 2013.

16. Guo J, Li HZ, Zhang WH, Wang LC, Wang LN, Zhang L, Li GW, Li HX, Yang BF, Wu L, et al: Increased expression of calcium-sensing receptors induced by ox-LDL amplifies apoptosis of cardiomyocytes during simulated ischaemia-reperfusion. Clin Exp Pharmacol Physiol 37: e128-e135, 2010. 
17. Weston AH, Geraghty A, Egner I and Edwards G: The vascular extracellular calcium-sensing receptor: An update. Acta Physiol (Oxf) 203: 127-137, 2011.

18. Rybczynska A, Jurska-Jasko A, Boblewski K, Lehmann A and Orlewska C: Blockade of calcium channels and AT1 receptor prevents the hypertensive effect of calcilytic NPS 2143 in rats. J Physiol Pharmacol 61: 163-170, 2010.

19. Rybczynska A, Lehmann A, Jurska-Jasko A, Boblewski K, Orlewska C, Foks H and Drewnowska K: Hypertensive effect of calcilytic NPS 2143 administration in rats. J Endocrinol 191: 189-195, 2006

20. Ogata H, Ritz E, Odoni G, Amann K and Orth SR: Beneficial effects of calcimimetics on progression of renal failure and cardiovascular risk factors. J Am Soc Nephrol 14: 959-967, 2003

21. Ortiz-Capisano MC, Reddy M, Mendez M, Garvin JL and Beierwaltes WH: Juxtaglomerular cell CaSR stimulation decreases renin release via activation of the PLC/IP(3) pathway and the ryanodine receptor. Am J Physiol Renal Physiol 304 : F248-F256, 2013.

22. Qu YY, Hui J, Wang LM, Tang N, Zhong H, Liu YM, Li Z, Feng Q and He F: Reduced expression of the extracellular calcium-sensing receptor (CaSR) is associated with activation of the renin-angiotensin system (RAS) to promote vascular remodeling in the pathogenesis of essential hypertension. PLoS One 11: e0157456, 2016.

23. Sun R, Zhang W, Zhong H, Wang L, Tang N, Liu Y, Zhao Y, Zhang T and He F: Calcimimetic R568 reduced the blood pressure and improved aortic remodeling in spontaneously hypertensive rats by inhibiting local renin-angiotensin system activity. Exp Ther Med 16: 4089-4099, 2018.

24. U.S. National Institutes of Health: Laboratory animal welfare: Public Health Service policy on humane care and use of laboratory animals by awardee institutions; notice. Fed Regist 50: 19584-19585, 1985.

25. Chi J, Meng L, Pan S, Lin H, Zhai X, Liu L, Zhou C, Jiang C and Guo H: Primary culture of rat aortic vascular smooth muscle cells: A New Method. Med Sci Monit 23: 4014-4020, 2017.

26. Valero MS, Pereboom D, Barcelo-Batllory S, Brines L, Garay RP and Alda JO: Protein kinase A signalling is involved in the relaxant responses to the selective $\beta$-oestrogen receptor agonist diarylpropionitrile in rat aortic smooth muscle in vitro. J Pharm Pharmacol 63: 222-229, 2011.

27. Yamaguchi T, Ida T, Hiraga M, Oishi K, Uchida MK and Echizen $\mathrm{H}$ : Effects of angiotensin II receptor blockers, angiotensin converting enzyme inhibitors, 3-hydroxy-3-methyl glutaryl (HMG) CoA reductase inhibitors, amlodipine and epalrestat on cultured basilar artery smooth muscle cell proliferation. Yakugaku Zasshi 124: 159-163, 2004.

28. Kim JE and Choi HC: Losartan inhibits vascular smooth muscle cell proliferation through activation of AMP-activated protein kinase. Korean J Physiol Pharmacol 14: 299-304, 2010.

29. Yamamura A, Ohara N and Tsukamoto K: Inhibition of excessive cell proliferation by calcilytics in idiopathic pulmonary arterial hypertension. PLoS One 10: e0138384, 2015.

30. Livak KJ and Schmittgen TD: Analysis of relative gene expression data using real-time quantitative PCR and the 2(-Delta Delta C(T)) method. Method 25: 402-408, 2001.

31. Kobayashi-Torii M, Takahashi Y, Sunanaga J, Fujita M, Lee EY, Ichimaru Y, Fujita T, Kanmura Y and Kuwaki T: Possible participation of extracellular calcium-sensing receptor in blood presure regulation in rats. Brain Res 1367: 181-187, 2011.
32. Smajilovic S, Hansen JL, Christoffersen TE, Lewin E, Sheikh SP, Terwilliger EF, Brown EM, Haunso $S$ and Tfelt-Hansen J: Extracellular calcium sensing in rat aortic vascular smooth muscle cells. Biochem Biophys Res Commun 348: 1215-1223, 2006.

33. Maillard MP, Tedjani A, Perregaux C and Burnier $\mathrm{M}$ : Calcium-sensing receptors modulate renin release in vivo and in vitro in the rat. J Hypertens 27: 1980-1997, 2009.

34. Ström A, Franzén A, Wängnerud C, Knutsson AK, Heinegård D and Hultgårdh-Nilsson A: Altered vascular remodeling in osteopontin-deficient atherosclerotic mice. J Vasc Res 41: 314-322, 2004.

35. Lai YM, Fukuda N, Su JZ, Suzuki R, Ikeda Y, Takagi H, Tahira Y and Kanmatsuse K: Novel mechanisms of the antiproliferative effects of amlodipine in vascular smooth muscle cells from spontaneously hypertensive rats. Hypertens Res 25: 109-115, 2002.

36. Yi B, Cui J, Ning JN, Wang GS, Qian GS and Lu KZ: Over-expression of PKGI $\alpha$ inhibits hypoxia-induced proliferation, Akt activation, and phenotype modulation of human PASMCs: The role of phenotype modulation of PASMCs in pulmonary vascular remodeling. Gene 492: 354-360, 2012.

37. Dickhout JG and Lee RM: Apoptosis in the muscular arteries from young spontaneously hypertensive rats. J Hypertens 17: 1413-1419, 1999

38. Song L, Gao LN, Wang J, Thapa S, Li Y, Zhong XB, Zhao HW, Xiang XR, Zhang FG and Ji P: Stromal Cell-derived factor-1 $\alpha$ alleviates calcium-sensing receptor activation-mediated ischemia/reperfusion injury by inhibiting caspase-3/caspase-9-induced cell apoptosis in rat free flaps. Biomed Res Int 2018: 8945850, 2018.

39. Mcconkey DJ and Orrenius S: The role of calcium in the regulation of apoptosis. Biochem Biophys Res Commun 239: 357-366, 1997.

40. McConkey DJ and Orrenius S: Signal transduction pathways to apoptosis. Trends Cell Biol 4: 370-375, 1994.

41. Schiffrin EL and Touyz RM: From bedside to bench to bedside: Role of renin-angiotensin-aldosterone system in remodeling of resistance arteries in hypertension. Am J Physiol Heart Circ Physiol 287: H435-H446, 2004.

42. Gomes RA, Teodoro Ld, Lopes IC, Bersanetti PA, Carmona AK and Hial V: Angiotensin-converting enzyme in pericardial fluid: Comparative study with serum activity. Arq Bras Cardiol 91: 156-161, 2008 (In English, Portuguese).

43. Intengan HD and Schiffrin EL: Vascular remodeling in hypertension: Roles of apoptosis, inflammation, and fibrosis. Hypertension 38: 581-587, 2001.

44. deBlois D, Orlov SN and Hamet P: Apoptosis in cardiovascular remodeling-effect of medication. Cardiovasc Drugs Ther 15: $539-545,2001$.

45. Tea BS, Der Sarkissian S, Touyz RM, Hamet P and deBlois D: Proapoptotic and growth-inhibitory role of angiotensin II type 2 receptor in vascular smooth muscle cells of spontaneously hypertensive rats in vivo. Hypertension 35: 1069-1073, 2000.

This work is licensed under a Creative Commons Attribution-NonCommercial-NoDerivatives 4.0 International (CC BY-NC-ND 4.0) License. 